\title{
Bodies that (Don't) Matter: Regulating Race on the Toilet in Kathryn Stockett's The
}

\section{Help}

Christopher Lloyd, University of Hertfordshire

"I think if God had intended for white people and colored people to be this close together for so much of the day, he would've made us color-blind" exclaims Minny, a black maid in Kathryn Stockett's novel The Help (2010). ${ }^{1}$ This bestselling drama about domestic servants in 1960s Mississippi (also adapted onto film by Tate Taylor in 2011) circles around the proximity of black and white women in the U.S. South. So "close together," and far from "color-blind" these women are forced to confront one another's bodies. The white women of The Help frequently cannot understand or confront blackness, in all its embodied and lived materiality. In attending to the novel's investment in feces and urination, this article will explore the visceral corporeality represented in Stockett's novel.

The narrative concerns a white southern writer-Miss Skeeter-who, on seeing the daily struggles of the black servants that sustain her domestic Mississippi world in Jackson, decides to write down the lives of these women. Skeeter thus embarks on a difficult project of interviewing local maids, starting firstly with Aibileen (her friend's maid), and later many other black women from the town. Eventually, the interviews become a book-Help - that is a bestseller across the nation, especially in Skeeter's own town of Jackson. Skeeter's narrative clearly mirrors Stockett's own, as she is a white woman who was raised in the South by a black woman. She sees the novel as a response to that particular past: it is a form of both personal and cultural memory. Stockett is certainly not the first white author to represent this key southern relationship: Lillan Smith's Killers of the Dream (1949) and Ellen Glasgow's The Woman Within (1954) are memoirs featuring memories of their "mammys"; 
more recently, Tony Kushner's musical Caroline, or Change (2003) connects the lives of a young white Jewish gay man and his family's black maid. The tradition of white writers excavating memories of the South's reliance on black labor continues into the twenty-first century and is sure not to disappear soon. Literature's role in the "production of cultural memory," Astrid Erll tells us, is an "ongoing process, characterized by a dynamic interplay between text and context, the individual and the collective, the social and the medial," and thus we must attend to the mediation of the southern past in The Help. ${ }^{2}$

While public responses to the novel and film have been largely positive, ${ }^{3}$ those in the academy have problematized The Help in a number of ways, most particularly in relation to the representations of race. ${ }^{4}$ This article will intervene in critical accounts of the book by focusing on the matter of embodiment and bodily processes, suggesting that Stockett's novel demonstrates the central tensions and disavowals of race-relations in the Civil Rights South through its attention to toilets, feces and urination. In his History of Shit, Dominique Laporte suggests that "socialization is regularly subverted by the politics of waste" in that "To touch, even lightly, on the relationship of a subject to his shit, is to modify not only that subject's relationship to the totality of his body, but his very relationship to the world."5 Thus, reading The Help's representations of toiletry illuminates the workings of socialization as it emerges in the distance from, and proximity to, human waste, particularly as is dramatized in the segregation-era southern home. Additionally, Karl Abraham argues that in the psychoanalysis of neurotics, "we are accustomed to find that anal and urethral sensations are closely related to infantile impulses of love," though these feelings can also develop into sadistic impulses and the release of unbearable unconscious affect. ${ }^{6}$ Bodily processes are intimately tied to psychic processes. In short, psychoanalytic accounts of bodily procedure augment Laporte's understanding of socialization and its undoing through waste. Developing a reading of The Help through Abraham's theories of excretion, Sigmund Freud's “anal character" and Sandor 
Ferenczi's concept of "hysterical materialization," this article will argue that the frequency with which Stockett's characters speak about, and concern themselves with, feces and urine testifies to a psychosomatic processing of race in the southern home.

Other than Tikena Foster-Singletary (2012) and Stephanie Rountree's (2013) studies of the novel, the significance of corporeality in The Help has been largely overlooked; the Southern Cultures special issue on the novel from 2014 investigates many aspects of the text, but little time is spent discussing the role of the physical lived body in it. Southern studies in recent years has oriented our attention towards the material nature of the South; see, for example, Martyn Bone's The Postsouthern Sense of Place in Contemporary Fiction (2005) or Scott Romine's The Real South: Southern Narrative in the Age of Cultural Reproduction (2008). Both texts alert us to the inconsistency or contingency of southernness - they argue it is not fixed-but we therefore have to attend to the particularities and assemblages of place and habitation that are rooted in precise historical and cultural moments.

Jay Watson's Reading for the Body (2012) is a key example of this turn in southern studies that develops and extends our vocabulary for thinking about corporeality in the South. Watson argues that "literary and artistic representations of the South are abundantly peopled with remarkable bodies" and they thus "offer a revealing window onto the problems, complexities, and cultural logics informing lives and identities in the twentieth-century U.S. South," which I want to extend on into the twenty-first century. ${ }^{7}$ To examine how The Help's bodies reveal the cultural logics of the region - that is, the way in which black bodies are relied upon, but disavowed, producing a hyper-awareness of the body and its processes-I want to augment and build on Rountree's suggestions that "Stockett's pervasive trope of consumption, digestion, and expulsion figuratively communicates the novel's Civil Rights ethos" by focusing further on the ways in which toilets and waste-processing are presented in the novel. ${ }^{8}$ While Rounteee argues that the "digestional tropes" merely establish character 
identity "through an integrated process between physiology ... and psychology," I want to argue that psychoanalytic theories of the digestion and anality help frame The Help's investments in racial demarcation and regulation in more intimate and complex ways. ${ }^{9}$ Christina Sharpe might call this a registering of "monstrous intimacies": the "everyday horrors that aren't acknowledged to be horrors," constituted by slavery's (after)effects. ${ }^{10} \mathrm{Jim}$ Crow laws and ideology attempted to segregate and delineate public spheres for black and white Americans, thus affecting the lived reality for many in the South. The Help's attentiveness to waste-processing shows the bodily mechanics of racial discrimination in the postbellum South. In short, The Help's obsession with urine and excrement demonstrate the ways in which the southern body is raced, constrained and regulated through monstrous intimacy.

To follow Judith Butler - from whom I have borrowed this title - a necessary project in understanding the creation and sustenance of identity is to "reformulate the materiality of bodies." "To do so, we recast "the matter of bodies as the effect of a dynamic of power, such that the matter of bodies will be indissociable from the regulatory norms that govern their materialization and the signification of those material effects." ${ }^{2}$ While Butler here is principally thinking about gender and sex, we can nonetheless align her argument with The Help's investment into the material substance of race and corporeality in the South. The matter of black female bodies in this world are effects of power structures that both materialize such bodies as black and female, but also legible as such, with particular meanings and significations. Focusing on bodily waste, in particular, enables a critical reflection on The Help that does not ignore its troubling politics but rather asserts its significance in understanding the workings and machinations of racism. Rountree argues that “in light of The Help's role as cultural artifact of Civil Rights memory-and-history and considering its undeniable contribution to contemporary U.S. American imagination, it is too 
costly to dismiss Stockett's work"; ${ }^{13}$ similarly, Suzanne W. Jones suggests that it is not surprising that "a novel which addresses race relations during a time marked by racial violence and social upheaval" published in the so-called "post-racial" twenty-first century, "has become one of the most talked about books and films" of the age. ${ }^{14}$ While critics of The Help say that its politics and representations are problematic and naïve,${ }^{15}$ I would argue that an interest in the book's corporeality materializes the complexities of segregation in southern memory that refuses to be flushed away.

\section{Bathroom Politics}

Bodily waste (feces and urine) are referenced so frequently in the text by both black and white characters. On the first page, Aibileen tells us, of her white employers' children: "I know how to get them babies to sleep ... and go in the toilet bowl before they mamas even get out a bed" (1). In the relations between black and white, adult and child, toilet habits are set from the start. It is as though Stockett wants us to see toiletry as central to this domestic southern world. Later on, a workman at the home of the Lefolts asks Aibileen "Where might I go to make water?" (20). Describing these facilities, Aibileen says how "[i]n the mornings, that bathroom seat get so cold out there, give me a little start when I set down" (90). The physicality of both needing the toilet, and using it, are given due attention in this narration. Further on in the novel, Aibileen asks Skeeter (referring to the current state of race-relations): "[d]id you hear about the colored boy this morning? One they beat with a tire iron for accidentally using the white bathroom?" (103). The political (and physical) stakes of using the "correct" bathroom - expelling waste properly — are clear to see here. The key example I want to focus on, however, relates to the character of Hilly: the most racist character in the book, and the one of most interest to this framework. 
During a card game with her white society friends at the house of Miss Lefolt (whose home is maintained by Aibileen), Hilly needs to use the toilet. Again, it cannot be overstated how often the characters use the bathroom, something usually un-mentioned in novels. Miss Lefolt tells Hilly "I wish you'd use the guest bathroom" (7), but Hilly is aware that this very toilet is also used by Aibileen, the maid. Responding, Hilly says "wouldn't you rather them take their business outside?" (8). This fear of black excretion emerges because Hilly thinks it "plain dangerous. Everybody knows they carry different kinds of diseases than we do" (8). Thus, Hilly creates the "Home Help Sanitation Initiative" which is a "disease-preventative measure" (8). The initiative lists reasons for the outside toilet including firstly, "99\% of all colored diseases are carried in the urine" and also "whites can become permanently disabled by nearly all these diseases because we lack immunities coloreds carry in their darker pigmentation" (158). The bill additionally lists the fact that "white diseases" may also harm black people, meaning everyone should "Protect yourself. Protect your children. Protect your help" (158). While this last comment ostensibly suggests that Hilly wants to safeguard both black and white people from the toilet's apparent disease-fostering, it should be clear that the initiative is a racist schematization of bodies. If urine (and feces) contains "black" diseases, and white people are vulnerable to them (because they are not "immune") then toiletry emblematizes and substantiates the racial fears and prejudices of Jim Crow. In short, Hilly wants to literally "put outside" black waste so that does not make her sick and vulnerable.

This initiative is, I suggest, a domestication of Jim Crow ideology and practice. Those American laws that legalized segregation in the public sphere are embedded in the home: the prized locus of American life and fantasy. While, as Grace Elizabeth Hale points out, "the increasing segregation of ... southern society made the white home ... seem like an island of racial mixing in a sea of separation," its integrative potential "was itself questionable," not least because of outside toilets like the ones Hilly wants to create. ${ }^{16}$ In essence, for Hale, 
"The white home served as a major site in the production of racial identity precisely because ... racial interdependence was both visible and denied." ${ }^{\prime \prime}$ This tension is something I want to explore through analysis of the role of toilets and toiletry. Similarly, as Laporte argues, "If waste ensconced itself in the home, and consequently in the private sphere ... it must certainly have played a role in the emergence of family and familial intimacy."18 While Laporte is tracing the long history of feces, particularly in Europe, his insights into the social function of bodily waste- how it partakes in the production and sustenance of familial roles and cultural spaces - enhance our understanding of toiletry in the segregation South and its homes.

The "Home Help Sanitation Initiative" is clearly as pernicious as the segregation of public places where southern whites enforced an "excision of certain ... bodies raced as black, from places of coexistence"; for here, the private and personal also becomes a site of segregation and racial coding. ${ }^{19}$ Distilling such ideology into the home-space evinces the pervasiveness of racism at this time. ${ }^{20}$ Indeed, in both the book and film, it the casualness of the Jackson women's bigotry - the ways in which it exists in the very fabric of their daily life - that is perhaps most shocking. The larger region (and nation's) attempted regulation of race in this novel happens in, and through, the bathroom. It is important to track the encoding of race in The Help's domestic spaces as "The white home became a central site for the production and reproduction of racial identity precisely because it remained a space of integration within an increasingly segregated world., ${ }^{21}$

To consider the southern bathroom, furthermore, is to revisit Patricia Yaeger's contention that female writers from the South have been largely overlooked in academic study for their ostensible interest in "small" domestic scenes and landscapes. "Whereas canonized [male] writers ... write toward the panoramic view, the big picture, women ... seem more intrigued by that slice of life ... with its shrewd, half-made torsos, its bodies in 
shreds," Yaeger writes. ${ }^{22}$ In short, female writers, no less interested in the issues investigated by Faulkner and others, focus on "smaller" scenes to probe the "connections between the body's intimacies and its civic demands." ${ }^{, 23}$ Yaeger makes a startling demand for southern scholars (which, though made in 2000, still needs attention): "We need to reenvision, from within the confines and rebellions of this 'lower' southern world, the eccentric work that women's writing performs on behalf of the dailiness of southern history." 24 Focusing on The Help's bathrooms, particularly, helps to envision that "dailiness" of the South's past.

Hilly's outdoor toilet initiative is clearly a product of the fetishistic disavowal of blackness. In displacing blackness (and black bodily products) out of the home, the white women of Jackson disavow the fact that it is these very black women (and their bodies) who are sustaining, creating, and propping-up white femininity. The mammy figure, Hale argues, reveals "a desperate symbolic as well as physical dependence on the very people whose full humanity white southerners denied and the centrality of blackness to the making of whiteness." ${ }^{25}$ Such a logic hinges upon a key disavowal: the refusal of blackness is twinned with the dependence on it. As Hegel's famous dialectic shows, the slave-master's rule over the slave coexists with the master's dependency on their laborers. Richard Godden has termed this the "primal scene" of slavery: "that unthinkable and productive episode during which the master both recognizes and represses the fact that since his mastery is slave-made, he and his are blacks in whiteface." ${ }^{26}$ For Godden, this moment (which he notes through the work of Faulkner) is central to slaveholding societies and their fictions. It is the principle disavowal that structures slave/master relations and continuously haunts them. Tracing the process of avowal and disavowal-of understanding white people's dependence on, and rejection of, black people-illuminates the central psychological dilemma of Stockett's contemporary novel too as the legacy of slavery informs Jim Crow ideology so clearly. ${ }^{27}$ Hilly's obsession with getting rid of black bodily excess - through the toilet initiative- 
reveals this racial entwining: it is as though the white women need to keep talking about black toilet habits in order to keep going themselves. Their inability to process and digest racial divisions (and bodily similarity) is tantamount to psychosomatic constipation.

Put another way, there is a lot of waste-processing in this novel that is also surely loss-processing. For Melanie Klein, the expelling of excrement is closely connected to the expelling of tears, and that for one in mourning, loss can be processed by bodily evacuation. In giving physical substance to mental absence, loss might be apprehended: she suggests that "the mourner ... expresses his feelings and thus eases tension" by crying or excreting feces. ${ }^{28}$ Similarly, as we saw for Karl Abraham, "an explosive evacuation of the bowels" for instance "can offer to the unconscious of the neurotic a substitute for a discharge of angry affect that has not taken place": getting something out physically replaces a psychic emptying out. The southern women of The Help, then, who are attempting to regulate bodily waste are also attempting to regulate loss and what is interior or exterior to the body. The disavowal of blackness involves, in a sense, an unconscious acknowledgement that bodies are not different after all, that race is not an impermeable dividing line. So, the loss that these women cannot face - the loss of an imagined racial certainty - is embodied through the toilet and investment in it.

\section{Anality}

We can also read this attention to the toilet in relation to Freud's anal stage of psychosexual development. In his brief 1908 paper "Character and Anal Erotism," Freud outlines the anal character-one trapped in this phase of development-as "especially orderly, parsimonious and obstinate." 29 These character traits of cleanliness, avarice, defiance and rage (as he lists them) clearly define the white women in The Help. Hilly and friends are defiantly rigid in the 
controlling and delimiting of their homes. Freud also suggests that anal characters, as infants, "belonged to the class who refuse to empty their bowels when they are put on the pot" because they derive subsidiary pleasure from defecating; so much so, that they remember "doing all sorts of unseemly things with the faeces." 30 This "erotogenicity of the anal zone" the psychosexual importance of the anus and its associated processes and products - is strong for the anal character, informing their psychic and somatic development. In Freud's view, those anal traits of orderliness and so on are possibly a "reaction formation against an interest in what is unclean and disturbing and should not be part of the body." ${ }^{31}$ For Freud, the anal character is in some ways rooted in the sadistic drive to control the self and other. Getting rid of certain "uncleanliness" is at once necessary and pleasurable: the anal child enjoys defecation so much that they retain and expel it at will. Such psychosomatic processes, however, become transformed in later life so that the anal character-here, Hilly-becomes overly invested in orderliness and expelling that which "should not be there." Hilly's obsession with the cleanliness and hygiene of white and black toilets comes into focus. The other white women of the town (Skeeter excluded) similarly have issues with waste, and are significant examples of the anal character. Their focus on toilets, however, has various (disastrous) consequences.

As the novel progresses, it becomes clear that in the focus on black waste, the white anal characters ignore important developments in their own home. Miss Lefolt, particularly, disregards her own child's (Mae Mobley's) difficulties in using the bathroom. We are introduced to this child's toilet-habits on the first page (quoted above), and learn that Aibileen is potty-training Mae Mobley. Aibileen says that these weeks of potty-training are "real important" for Mae Mobley, telling the reader "you probably don't remember the first time you went to the bathroom in the toilet bowl" (92). Lefolt herself is uninterested in helping this process, so it is left to Aibileen to take care of (nothing exemplary in the world of 
black maids, of course). In fact, the only relationship Lefolt has to her daughter is one of punishment: she frequently smacks her daughter's legs, making her cry, leaving "red fingermarks" (19). Aibileen knows that training a child involves care and attention (not scolding) in addition to physically showing her how to use the toilet. As Lefolt does not want to do this, and Aibileen cannot use the inside bathroom, she secretly takes Mae Mobley outside to hers. This has disastrous consequences when, at a later date, Mae Mobley instinctively uses Aibileen's toilet in front of her mother. After punishing her again - and thus stunting the potty-training process - she tells her daughter that "I did not raise you to use the colored bathroom!" (95). Lefolt, like Hilly, shows qualities of the anal character, here directing her aggression and sadism towards her daughter. Lefolt's disavowal "infects" and "harms" her daughter in ways far more dangerous than the mythic black diseases. Mae Mobley is affected by her mother's inability to work-through and expel her loss (of mastery). In a later scene, which I will come to below, Mae Mobley runs to a used toilet that has been dumped on Hilly's front lawn: "she done pulled down her panties and tinkled in it" (288), Aibileen tells us. ${ }^{32}$ In the novel, luckily no-one but Aibileen notices. In the film, however, Miss Lefolt witnesses this scene; she smacks her, as in the example above, and does serious damage to Mae Mobley's toilet-training, and thus the child's own relationship to corporeality and waste.

Eventually, though, the Jackson women's obsession with toilets and black waste gets traumatically and comically thrown back in their faces, often quite literally; I offer three key examples of this. The first instance is perhaps the most affecting, as it involves a white woman like Skeeter who is not racist; in fact, she is one of the only women in Jackson who welcomes the maid Minny into her home (even though she is still an employee). Celia Foote was a poor white woman who has married into money. In this new domestic role, she does not know what to do with her time, or how to look after the home. Thus, she employs Minny 
to help her. On their first meeting, Celia asks Minny "Can I get you a cold drink? ... Set down and I'll bring you something" (31), actively overturning the typical roles of a white and black woman in the home. When Minny accepts the job, Celia "laughs and the crazy woman goes to hug [Minny]" (31), but Minny avoids this contact as she is aware of the regulations of racial intimacy. Celia, however, is unconcerned with these societal restrictions. At the end of the novel, once Celia has learned how to cook, she prepares a feast for Minny to thank her for helping in the house. This saccharine, but affecting, scene is illustrative of Celia's good nature and resistance to the segregationist codes that dominate the thinking of most women in the novel.

One day, though, Celia miscarries her baby. She locks herself in the bathroom, and suddenly becomes quiet; Minny worries and breaks open the door. There she finds Celia on the floor, covered in blood. It saturates the white bathroom so that it is "embedded in the grout" (232). Symbolically, bodily excess stains the white female façade. Minny notes that she "can see blood in the toilet bowl. A lot of it" (232), along with the miscarried fetus. This spectacle of traumatic motherhood and femaleness seemingly has to occur in the bathroom, because this is The Help's physical and psychic site of bodily vulnerability and (un)controllability. Minny understands that Celia's unspoken words to her are "[w]ill you fish my dead baby out of that toilet bowl?" (233). Here, Celia's bodily and female losses are connected (as in the racist imaginings of the southern bathroom). But in this household, Celia is far from racist: she actively blurs the lines between Minny and herself, so that the impermeable dividing line set up by Hilly and the other whites is made porous. Because Celia is poor, she is looked down upon by the other women of the town, especially Hilly, and conceived of as nothing but "white trash." In a sense, she may not be able to live up to the ideals of white womanhood - the southern Belle figure, and its legacy - that are so enshrined in this region's culture. ${ }^{33}$ We could possibly argue, then, that Hilly has to lose her child in this 
bathroom because the southern regulation of bodies, waste and race has been trespassed by her. In actively welcoming Minny into her home, Celia not only transgresses the "sanitation initiative," but also its underpinning racist logic. It is as though Celia's contravention of Jim Crow produces traumatic bodily results. This must end in the bathroom: the site of all the literal and metaphorical shit that cannot be dealt with in this fractured southern world..$^{34}$

My other examples relate specifically to Hilly and two ways in which she is confronted by her obsessions with toiletry. As Rountree argues, the "endurance" of the toilet initiative "depends on the ability to establish and fortify clear physical and mental boundaries that separate racialized bodies," but as the novel progresses it becomes clear that the toilet initiative actually unravels rather than fortifies racial segregation. ${ }^{35}$ Firstly, Hilly asks Skeeter to put a note in the local newsletter that people in the town should drop off their used coats on her lawn to be resold. However, Skeeter misprints "coats" in the letter, writing "commodes" instead, causing a comic spectacle of toilets to amass on Hilly's garden. Aibileen witnesses the sight of "Pots. Right smack on Miss Hilly's lawn. All different colors and shapes and sizes" (287). For now, note that the commodes are of different "colors and shapes and sizes," perhaps a reference to the multiracial and multicultural nature of this divided Mississippi. While everyone assumes that Skeeter misprints this advertisement purposefully and punishingly, in her narration she admits that she "hadn't planned it at all. When I started typing out [Hilly's] initiative for the newsletter ... something cracked open inside of me, not unlike a watermelon" (345). Putting aside the racialized connotations of watermelons, which are perhaps problematic, significant here is the fact that Skeeter becomes internally fractured, affected by Hilly's racism and ignorance. It makes her unconsciously write "commodes" over "coats," as though suggesting how far this obsession with toiletry has seeped into consciousness. Moreover, the liquidity of the internal "watermelon" symbolically remains in the world of excretion. Ultimately, this scene dramatizes a kind of "return of the repressed," 
as Hilly's obsession with toiletry literally returns on her lawn and front steps. Hilly's anality, which manifests as an obstinate cleanliness (while simultaneously rooted in a controlled enjoyment of fecal waste), is literalized in front of her house.

\section{Psychic/Somatic Materializations}

The second, more complex, example I want to offer revolves around the relationship between Hilly and Minny (before she goes to work for Celia); specifically, with regards to an event that is kept secret for some time. Minny reveals this shocking and embarrassing story to Celia, Minny, and Skeeter, to act as a kind of insurance for the black maids who tell their intimate stories about the women of Jackson. Because Hilly does not want this story to emerge as being about her, she does everything she can to make the local people think the stories in Help are not about their town. Ultimately, Minny reveals to the other women that she has done something horrendous. After Hilly fires Minny-because she suspects her of stealing, among other things-Hilly condescendingly offers her some money. Minny's response: "I tell her to eat my shit" (339). The next day, Minny returns to Hilly's house, to "apologize," bringing Hilly her favorite chocolate pie. As Hilly eats it, with her mother watching and enjoying every mouthful, she asks what is in the recipe. Other than the chocolate custard filling, and Mexican vanilla, Minny reveals "what else she put in that pie" (339). She's literally fed Hilly "her shit." As Hilly understands what has occurred-her ageing mother finds this hilarious - Minny says that "I wouldn't go tattling on Minny either, or you'll be known all over town as the lady who ate two slices of Minny's shit" (339). Hilly does everything in her power to stop this story from emerging as public knowledge, but I want to read this event in two ways because it seems to interestingly consolidate The Help's investment in waste and race. 
Firstly, we could argue that it is actually very necessary that Hilly "eats shit" as it allows Minny a form of revenge that relates most precisely to Hilly's fears and disavowals of waste. It is as though Hilly needs to ingest black waste in order to really process it and the racial meanings associated therein. However, Hilly immediately represses this event and its horror, refusing to admit that it happened. In this first reading, then, Minny confronts Hilly with her own disavowals. Secondly, though, we have to acknowledge how strangely problematic this scene is. That chocolate and feces are mingled together in the pie cannot but intertwine chocolate (and its racial/racist connotations of blackness) with feces; thus, blackness and feces are substantively linked. Minny, moreover, famous for her cooking, is even more famous for this particular chocolate pie: entrenching the connection even further. Jennifer Nash has explored what she calls black anality, a term which describes how frequently "black pleasures are imagined to be peculiarly and particularly oriented toward the anus, and thus as peculiarly and particularly attached to anal ideologies including spatiality, waste, toxicity, and filth." ${ }^{36}$ We could argue that the "shit pie" incident in The Help only serves to intensify and underscore the associations of black anality with what Rountree also sees as abjection.

While it is amusing that Hilly has to eat feces, it is also quite revolting; shit is forced upon Hilly by a clever (and deceitful) black woman. Even with the comic element present, there is something affective and shocking about this revelation. The potential disgust that this scene may cause in us implicitly connects blackness with revulsion, waste, and feces in ways that reflect and repeat the disastrous disavowal that the novel is presenting to us as problematic. Where Hilly (wrongly) suggests that blackness and feces need putting outside, Stockett has one of the black maids duplicitously bring it inside the home-inside the pie-in ways that are not entirely easy to stomach. "Hilly figuratively forces her racist politics down 
everyone's throat," Rountree argues, “so Minny physically forces her own political resistance down Hilly's." ${ }^{37}$ To push this analysis further, I turn back to a psychoanalytic framework.

Sandor Ferenczi’s essay “The Phenomena of Hysterical Materialization” (1919) develops - in highly original ways - the theories of excrement, both urinal and fecal, I have been investigating here. In general terms, Ferenczi suggests, after Freud, that "symptoms of conversion hysteria" are "representations of unconscious phantasies in bodily terms." ${ }^{38}$ Put simply, psychological issues manifest themselves in and on the body; in reverse, bodily symptoms - numbed limbs, stomach pain, itching — are representations (or manifestations) of unconscious fantasy or psychic material. While this more general sense of psychosomatic illness is interesting in relation to the anal character noted above, Ferenczi is also concerned with the neurotic and hysteric figure who has very specific relations to waste material that may shed light on The Help. I am not necessarily suggesting that Minny is a neurotic figure, but that Ferenczi's insights into such psychic states reveals much of significance here. For him, quite particularly, neurotics and hysterics are capable of internal fecal control, in that they can unconsciously perform "finely graduated and localized contractions" in the colon, "making it possible to retain a faecal mass or gas-bubble ... and compress, so to say, shape it." ${ }^{39}$ Ferenczi also helps us see that the hysteric's obsession with fecal control reveals a "complex ruled by ideas of possession, retention, and unwillingness to give up." ${ }^{40}$ Of course, this description seems to refer quite directly to Hilly and the other Jackson women who are unable to concede the knowledge of racial similarity; indeed, they reinforce racial boundaries to establish the opposite.

Yet, Ferenczi might also help us think further about Minny's pie as a kind of "gift" to Hilly that relates to this internal, unconscious controlling of fecal material. Producing a gift of her own feces-controlling it, shaping it (externally) like the hysteric-Minny might be revealing something of an unconscious wish. If, as Karl Abraham similarly writes, the 
"surrender of excrement" is a "gift" which reveals the anal character's infantile sexuality that has been repressed, what does Minny's chocolate pie represent? ${ }^{41}$ In Ferenczi's terms, too, the fecal mass is a "physical representation of an unconscious wish": a materialization of something internal in external form. ${ }^{42}$ For both Abraham and Ferenczi, manifesting and producing feces to another is a form of gift-giving-rooted in the childhood scene of an infant presenting feces to the parent-that is expressive of unconscious wishes and desires. The gift from Minny to Hilly is, in a sense, revenge: literalizing that phrase - "eat my shit" which no black maid could ever dream of uttering in the Jim Crow South. By forcing Hilly to eat this, in a form which she finds pleasurable, Minny is doubly hurting Hilly. But more than this, Hilly has to consume the troubling knowledge of racial otherness; she must take in the corporeality-its substance, its waste-of black women that she has been resisting, repressing and disavowing so strongly through her racist actions and toilet initiative. The unconscious (or perhaps conscious) wish of Minny here is to enact revenge, and to force Hilly into an uncomfortable relation to otherness. From childhood, we might say, Minny has interiorized inferiority and dispossession. She has learned, in her own lifetime, that her selfhood (her body) does not matter. The chocolate/shit pie is a manifestation of the troubled relationship black and white women have to embodiment.

To follow Ferenczi's thought further, "hysterical materializations," as he calls them, show the human body "in its entire plasticity." ${ }^{43}$ The hysteric's body is revealed as "plastic": as changeable, fluid, and far from static; a reformulation of the regulatory norms noted above. In light of the racial divisions that are trying to be upheld by the domesticated Jim Crow toilet initiative in The Help, thinking of the body as un-secure comes into focus. As Rountree argues, the novel's investigations into consumption reveal the "turning inside-out and destabilizing the boundaries of the body." ${ }^{44}$ If Minny's unconscious wish is to play with that interior substance which is considered dangerous and Other by the white women attempting 
to control it and siphon it outside of the home, perhaps such a materialization reveals even more about corporeality itself. Ferenczi suggests that the hysteric's organs "subordinate themselves entirely to the pleasure principle," and testify to a lack of biological rigidity and utility. "The stomach and bowel," he writes, "play puppet-games with their own walls and contents, instead of digesting and excreting" and the "skin is no longer the protective cover of the body ... [but] behaves like a genuine sexual organ." 45 The plastic body, which internally can shape and create feces as a form of gift-giving, is also one which submits itself to the pleasure principle. Digestive organs alter in their physicality, rather than aiding digestion itself; and the skin does not protect the body, but acts as a sexual organ (more than simply an erotogenic zone).

In The Help, through all of the southern women's devotion to toiletry-in their wanting to get rid of it, control it, use it as revenge - we see the fact of the body's instability, its porousness, its potency as site of psychic meaning, its very refusal to be regulated. One's body, for Ferenczi, is shown to be (through fecal materialization) a cluster of parts driven by an excess of desire. What, though, is this desire for? How does this toiletry function as fantasy and desire? Let us return to the central premise of the novel. Miss Skeeter is attempting to enable black voices to be heard and read. In circumventing her society's implicit rules, Skeeter fosters connections with black maids, helping them to tell their stories. Moreover, it is their (and our) knowledge of Hilly's eating feces that enables them to get away with telling the story. This scene seems to act in the novel as a central locus: a primal scene, of sorts, or a transformative moment in which the psychological and physical logics of The Help's South congeal. It is as if Stockett is at once repulsed by this idea-of forcing blackness, and black waste, outside - and also entranced by it. The novel circulates around toilets (and storytelling) so precisely that it demands to be read in a psychoanalytic way. If, then, the chocolate/shit pie is the key to this novel, then we must think about its implications. 
For the stories of black women to be told in this southern world, they seemingly have to rely upon the white world's obsession with black waste. It is because of Hilly's problems and investments in toiletry, that the maids (with Skeeter) are able to use this piece of information as insurance in the publication of Help. In a way, it is both problematic and necessary that Hilly disavows black feces so absolutely, as it both upholds and enforces segregation while simultaneously enabling and producing narratives that unpick, revise and resist such racist practices. Without that pie, Help would not be published, and the women of Jackson would not begin to question their involvement in this southern system. If only it were not a black woman who has to literally feed Hilly this knowledge. If only the white women would have to eat their shit without Minny spooning it into their mouths. Perhaps in Stockett's South, though, there could be no other way?

\section{The Matter of Race}

To turn, finally, to Butler's Bodies That Matter again, we might argue that in place of bodies and identities that are "natural" - as Hilly and her friends would like to believe-we need to attend to the notion of "matter." For Butler, matter is not a "site or surface, but ... a process of materialization that stabilizes over time to produce the effect of boundary, fixity, and surface we call matter. ${ }^{, 46}$ Perhaps in their attention to bodily processes and excrement, the white women of Jackson have refused to believe that corporeal matter is anything but solid and defined. Through Jim Crow segregation in the home, black matter and white matter have ostensibly been kept separate (all the while, black women have been creating and sustaining their very identity). This disavowal, which can be traced through the interest in feces too, is a way of keeping bodies in place. We could say that the southern women of The Help have continued to describe and reveal those bodies that matter, and those that do not. In Butler's 
terms, thinking through the normative regulation of bodies (as sexed, and gendered; as heteronormative, or queer) can help us see "what qualifies as a viable body." ${ }^{47}$ Bodies that do not become viable, in these terms, those that do not fit normative modes or models, fall out of sight in various ways. ${ }^{48}$ This hegemony of articulated bodies might just produce a rearticulation of what "qualifies as bodies that matter, ways of living that count as 'life,' lives worth protecting. ${ }^{\prime 49}$ Perhaps Hilly's, Stockett's (and my) attention to matter-feces and urine particularly-(however varied and differently invested) might be, as Butler invokes, an "enabling disruption, the occasion for a radical rearticulation of the symbolic horizon in which bodies come to matter at all." ${ }^{50}$ The Help's obsession with toiletry, then, while far from politically clean, is nonetheless an integral prism through which to untangle the complex politics at the heart of racial segregation, and the disavowals of embodiment that substantiate them.

If memory, and cultural memory particularly, "constructs the past in the present," Susannah Radstone writes, then what present needs is Stockett addressing? Is she, as Tara McPherson writes, "enshrin[ing] certain Souths and southerners while forgetting others"? ${ }^{51}$ In an afterword to the novel, titled "Too Little, Too Late," Stockett writes of the difficulties she faced in attempting to write naturally and persuasively as a black woman in servitude to a white household in the mid-twentieth century. She is aware, at least, of the problems involved in making this imaginative leap: "I was scared, a lot of the time, that I was crossing a terrible line, writing in the voice of a black person" (450). Stockett's main worry is that she would "fail to describe a relationship that was so intensely influential in my life, so loving, so grossly stereotyped in American history and literature" (450). This relationship-and the attendant structures of black servitude and white domesticity in the South - is clearly trying to be imaginatively remembered by Stockett, but this cultural memory has its limitations. As Valerie Smith argues, "Black women's memories play a central role in both the novel and the 
film" but "like many writers who have come before her [... Stockett] is clearly appropriating the stories and memories of the disenfranchised and using them to advance her own career., ${ }^{, 52}$ While debates about The Help will seemingly go on as long as the book is read, this article has argued that though the racial politics of the book may be troublesome, the novel equally troubles the idea of the raced body in the segregated South. I have shown how Stockett's representations of bodily waste reveal the psychic and somatic structures of a domesticated Jim Crow. We must continue to interpret Stockett's novel, and others like it, because of its attempt to mediate the southern past and the bodies consigned to it. 
Notes

1. Kathryn Stockett, The Help (London: Penguin, 2010), 215. Hereafter cited parenthetically.

2. Astrid Erll, Memory in Culture, trans. Sara B. Young (Basingstoke: Palgrave Macmillan, 2011), 171.

3. The cover and front pages of my paperback Penguin edition are emblazoned with the following (sometimes ridiculous) quotations: "The other side of Gone with the Wind - and just as unputdownable" (Sunday Times); "immensely funny, very compelling” and "Draws you ... into a world of okra and fried chicken" (Daily Telegraph); "laugh-out-loud" (Marie Claire); "a good old-fashioned novel” (New York Daily News); "wildly popular winning novel ... Book groups armed with hankies will talk and talk about [the characters'] quiet bravery and the outrageous insults dished out by their employers" (The New York Times). 4. See Suzanne W. Jones, “The Divided Reception of The Help," Southern Cultures 20, no. 1 (2014).

5. Dominique Laporte, History of Shit, trans. Nadia Benabid and Rodolphe el-Khoury (Cambridge, MA and London: The MIT Press, 2000), 29.

6. Karl Abraham, "The Narcissistic Evaluation of Excretory Processes in Dreams and Neurosis," in Selected Papers, ed. Ernest Jones, trans. Douglas Bryan and Alix Strachey (London: Hogarth Press, 1927), 319.

7. Jay Watson, Reading for the Body: The Recalcitrant Materiality of Southern Fiction, 18931985 (Athens: Univ. of Georgia Press, 2012), 9, 25.

8. Stephanie Rountree, "Poop, Pie, \& Politics in The Help: Rescuing the (Literary) Body from Political Obsolescence," Word and Text: A Journal of Literary Studies and Linguistics 3, no. 2 (2013): 61. 
9. Ibid.

10. Christina Sharpe, Monstrous Intimacies: Making Post-Slavery Subjects (Durham, NC:

Duke Univ. Press, 2010), 3.

11. Judith Butler, Bodies That Matter: On the Discursive Limits of "Sex" (London:

Routledge, 2001), xii.

12. Ibid.

13. Rountree, "Poop, Pie \& Politics," 70.

14. Jones, "The Divided Reception of The Help," 23.

15. See, for example, the Association of Black Women Historians, "An Open Statement to the Fans of The Help," ABWH, no date, http://www.abwh.org/images/pdf/TheHelp-

Statement.pdf (accessed June 25, 2016) and Duchess Harris, "Kathryn Stockett Is Not My Sister and I Am Not Her Help," The Feminist Wire (2011).

16. Grace Elizabeth Hale, Making Whiteness: The Culture of Segregation in the South, 18901940 (New York: Vintage Books, 1999), 87.

17. Ibid., 88

18. Laporte, History of Shit, 28.

19. Thadious M. Davis, Southscapes: Geographies of Race, Region, and Literature (Chapel Hill: Univ. of North Carolina Press, 2011), 11.

20. For more, see the definitive C. Vann Woodward's The Strange Career of Jim Crow (1955; repr. Oxford: Oxford Univ. Press, 2002), or the more recent The Jim Crow Routine: Everyday Performances of Race, Civil Rights, and Segregation in Mississippi (Chapel Hill: The Univ. of North Carolina Press, 2015) by Stephen A. Berrey.

21. Hale, Making Whiteness, 94.

22. Patricia Yaeger, Dirt and Desire: Reconstructing Southern Women's Writing, 1930-1990 (Chicago: The Univ. of Chicago Press, 2000), 153. 
23. Ibid.

24. Ibid., 154.

25. Hale, Making Whiteness, 113.

26. Richard Godden, Fictions of Labor: William Faulkner and the South's Long Revolution (Cambridge: Cambridge Univ. Press, 2007), 4.

27. See David M. Oshinsky, "Worse than Slavery”: Parchman Farm and the Ordeal of Jim Crow Justice (New York: The Free Press, 1997) and Ron Eyerman, Cultural Trauma:

Slavery and the Formation of African American Identity (Cambridge: Cambridge Univ. Press, 2001).

28. Melanie Klein, "Mourning and its Relation to Manic-Depressive States," in The Selected Melanie Klein, ed. Juliet Mitchell (New York: The Free Press, 1987), 162.

29. Sigmund Freud, "Character and Anal Erotism," in The Freud Reader, ed. Peter Gay (New York and London: W.W. Norton and Co., 1995), 294.

30. Ibid.

31. Ibid., 296.

32. Ibid., 288.

33. For further analyses of the lady figure, see Tara McPherson, Reconstructing Dixie: Race, Gender, and Nostalgia in the Imagined South (Durham, NC: Duke Univ. Press, 2003) and Elizabeth Fox-Genovese, Within the Plantation Household: Black and White Women of the Old South (Chapel Hill and London: The Univ. of North Carolina Press, 1988).

34. Another scene involving Celia, Minny and the bathroom comes when Celia's husband returns home early from work one day (ostensibly, he knows nothing of Minny's working at the house). Minny rushes into the bathroom to hide from him: "I see myself in the mirror over the sink. Crouched like a fool on top of a white lady's toilet" (53). The bathroom continuously acts as a locus for power, race and corporeality. 
35. Rountree, "Poop, Pie \& Politics," 64.

36. Jennifer C. Nash, "Black Anality," GLQ: A Journal of Lesbian and Gay Studies 20, no. 4 (2014): 439.

37. Rountree, "Poop, Pie \& Politics," 66.

38. Sandor Ferenczi, “The Phenomena of Hysterical Materialization: Thoughts on the Conception of Hysterical Conversion and Symbolism," in Future Contributions to the Theory and Technique of Psychoanalysis, ed. John Rickman, trans. Jane Isabel Suttie et al (New York: Boni and Liveright, 1927), 89-90.

39. Ibid., 94.

40. Ibid.

41. Karl Abraham, "Contributions to the Theory of the Anal Character," in Selected Papers, ed. Ernest Jones, trans. Douglas Bryan and Alix Strachey (London: Hogarth Press, 1927), 377.

42. Ferenczi, "The Phenomena," 95.

43. Ibid., 104.

44. Rountree, "Poop, Pie \& Politics," 63.

45. Ferenczi, "The Phenomena," 103.

46. Butler, Bodies That Matter, xviii.

47. Ibid., xxiv.

48. This is a project that Butler has considerably expanded in her more recent books

Precarious Life: The Power of Mourning and Violence (London: Verso, 2004) and Frames of War: When is Life Grievable? (London: Verso, 2009).

49. Butler, Bodies That Matter, xxiv.

50. Ibid., xxx.

51. McPherson, Reconstructing Dixie, 5. 
52. Valerie Smith, "Black Women's Memories and The Help," Southern Cultures 20, no.1 (2014): 28, 29. 